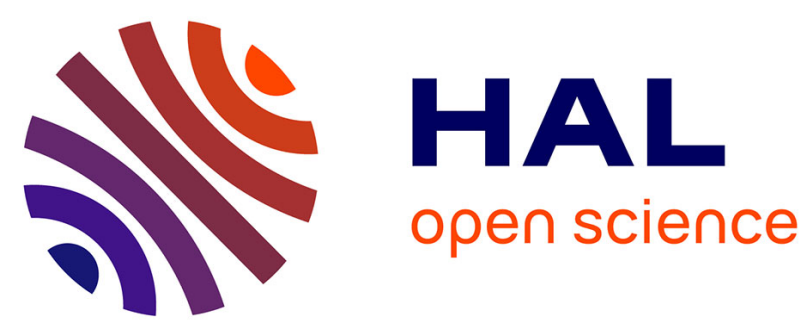

\title{
Ionospheric and Magnetic Signatures of a Space Weather Event on 25-29 August 2018: CME and HSSWs
}

\author{
W. Younas, Christine Amory-Mazaudier, Majid Khan, Rolland Fleury
}

\section{To cite this version:}

W. Younas, Christine Amory-Mazaudier, Majid Khan, Rolland Fleury. Ionospheric and Magnetic Signatures of a Space Weather Event on 25-29 August 2018: CME and HSSWs. Journal of Geophysical Research Space Physics, 2020, 125 (8), pp.e2020JA027981. 10.1029/2020JA027981 . hal-02926015

\section{HAL Id: hal-02926015 https://hal.science/hal-02926015}

Submitted on 31 Aug 2020

HAL is a multi-disciplinary open access archive for the deposit and dissemination of scientific research documents, whether they are published or not. The documents may come from teaching and research institutions in France or abroad, or from public or private research centers.
L'archive ouverte pluridisciplinaire $\mathbf{H A L}$, est destinée au dépôt et à la diffusion de documents scientifiques de niveau recherche, publiés ou non, émanant des établissements d'enseignement et de recherche français ou étrangers, des laboratoires publics ou privés. 
Younas Waqar (Orcid ID: 0000-0002-0410-7652)

Amory-Mazaudier Christine (Orcid ID: 0000-0002-5961-6331)

\section{lonospheric and magnetic signatures of a space weather event 25-29 August 2018: CME and HSSWs}

W. Younas ${ }^{1}$, C. Amory-Mazaudier ${ }^{2,3}{ }^{3}$, Majid Khan ${ }^{1}$, R. Fleury ${ }^{4}$

${ }^{1}$ Department of Physics, Quaid-i-Azam University Islamabad 45320, Pakistan

${ }^{2}$ LPP, CNRS/Ecole Polytechnique/Sorbonne Université/Université Paris-Sud/Observatoire de Paris, France

${ }^{3}$ T/ICT4D, The Abdus Salam International Centre of Theoretical Physics, Italy

${ }^{4}$ Lab-STICC/CNRS-UMR 6285, IMT-Atlantique Brest, France

Corresponding author: Waqar Younas (mrwaqar11@gmail.com)

\section{Key points}

- The partial ring current is an important parameter and must be taken into account for an accurate description of ionospheric disturbed current $\left(D_{\text {iono }}\right)$

- Storm-time generated thermospheric winds do not have uniform planetary extension.

This article has been accepted for publication and undergone full peer review but has not been through the copyediting, typesetting, pagination and proofreading process which may lead to differences between this version and the Version of Record. Please cite this article as doi: $10.1029 / 2020 J A 027981$ 
- Our study suggests the existence of ionospheric current cells, which is consistent with the theoretical model of Blanc \& Richmond (1980).

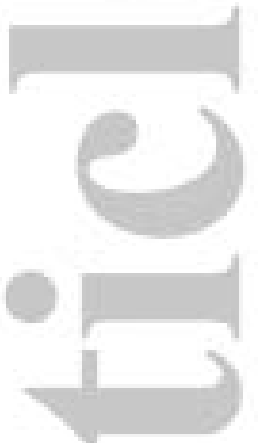

\section{Abstract}

We present a study concerning space weather event of 25-29 August 2018, accounting for its ionospheric and magnetic signatures at low and mid-latitudes. The effects of storm in several longitudinal sectors (Asia, Africa, America, and Pacific) have been analyzed using various parameters such as total electron content, geomagnetic field and column [O/N2] ratio. Positive ionospheric storms are found in all the longitudinal sectors having its maximum effects in the Asian sector. Whereas, the negative ionospheric storms have been observed in the summer (northern) hemisphere. A large decrease in [O/N2] ratio in the northern hemisphere is a possible cause of the observed negative storm effects. Ionospheric F2 region maximum electron density ( $\mathrm{NmF2}$ ) and total electron content (TEC) have shown a positive correlation during this storm. The study suggests that storm time generated wind does not have a uniform planetary extension and mainly affects dayside (America and Pacific) and dusk side (Africa) sectors. During the space weather event, we observe an asymmetric variations of the magnetic field as a function of the longitude. On the other hand, the magnetic variations at mid-latitudes are found to be symmetric in both hemispheres. A signature of the disturbance dynamo (anti-Sq circulation) has been observed, mainly at low-latitudes. We emphasize that the partial ring current (PRC), estimated by the ASYM-H magnetic index, must also be taken into account along with the SYM-H index for a better approximation of ionospheric currents. The study further suggests existence of several electric current cells in the ionosphere, which is consistent with the Blanc-Richmond model.

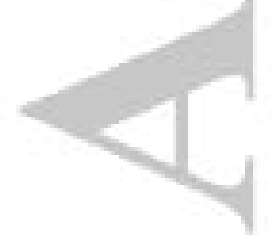




\section{Introduction}

Geomagnetic storms involve large energy inputs from the solar wind to the magnetosphere. The coupling zone between solar wind, magnetosphere, thermosphere, and ionosphere is called the auroral zone, which involves many physical processes, e.g. transmission of large magnetospheric convection electric field, auroral particle precipitation, field-aligned currents and large auroral electrojets. During a geomagnetic storm, the ionosphere of middle and low-latitude gets coupled with the auroral zone through different large-scale physical processes , e.g. the thermal expansion of the Atmosphere (Fuller-Rowell et al. 1994, 1996)), the prompt penetration of the magnetospheric convection electric field (Vasyliunas, 1970, 1972)) and the ionospheric disturbance dynamo (Blanc and Richmond 1980)

Many authors have modeled the ionosphere response to the geomagnetic storms: FullerRowell et al. (1994) first presented the effects of thermal expansion of the thermosphere during a geomagnetic storm. This process strongly influences the chemistry and composition of the neutral atmosphere. The enhancement in ionospheric electron density during storm is termed as positive storm effect while decrement in electron density is called negative storm effect. They found that ionospheric electron density variations during a geomagnetic storm, at a given point, strongly depend on the local time at the beginning of a storm. Fuller-Rowell et al. (1996) investigated the seasonal variations of ionosphere response and concluded that positive ionospheric storms are more likely to occur in the winter hemisphere, whereas negative storms have been predicted in the summer hemisphere.

Vasyliunas (1970) was the first to model the electric field due to particle motions in the magnetosphere. This electric field is transmitted from the auroral zone to middle and lowlatitudes and the process is known as prompt penetration of the magnetospheric convection electric field (PPEF). Vasyliunas (1970) study made it possible to model the magnetic signatures as reported by Nishida et al. (1968), who observed the variations in H-component of Earth's magnetic field (DP2) arriving simultaneously across the globe. The prompt penetration of magnetospheric convection electric field is characterized by 3 phases. During phase 1 , there is no shielding effect and the electric field of magnetospheric convection extends to low latitudes. During the second phase, after 30 minutes: there is a shielding (Vasyliunas, 1972). The electric field of magnetospheric convection is no longer active at low latitudes because the developed space charge in the magnetosphere produces an opposite 
electric field. Finally, followed by third phase of over shielding (Kobéa et al., 2000) effect of the electric field of magnetospheric convection affects again low latitudes and this is linked to the aligned currents of region 2 (Peymirat et al., 2000).

Blanc \& Richmond (1980) modeled the disturbance of ionospheric electric currents and associated magnetic disturbance, as caused by Joule energy dissipation in the auroral zone. This physical process is known as ionospheric disturbance dynamo electric field (DDEF). Blanc \& Richmond (1980) predicted two cells of circulation in ionospheric electric currents, which move in a clockwise (anti-clockwise) direction in a cell closest to the equator (poles). Several experimental studies have been presented regarding the electrodynamic coupling between high and low-latitudes:

Fejer et al. (1983) reported two signatures, namely PPEF and DDEF on electric field measurements made by the incoherent scatter sounder at Jicarmaca $\left(12^{\circ} \mathrm{S}, 77^{\circ} \mathrm{W}\right)$. Later studies on magnetic signatures of ionospheric currents have revealed the existence of antiSq variations at low-latitudes during the post-storm days, which is also a main prediction of the Blanc-Richmond model. Recently, Le Huy \& Amory-Mazaudier (2005) analyzed the magnetic perturbations associated with the ionospheric disturbance dynamo (Ddyn) during the post-storm magnetic quiet days, when the disturbance polar type 2 (DP2) is null. Fathy et al. (2014) studied the Ddyn variations by various filter techniques. More recently, Nava et al. (2016), Migoya-Orue et al. (2016), Rodriguez-Zulaga et al. (2016), Zaourar et al. (2017) and Kashcheyev et al. (2018) explored various geomagnetic storms using different data sets, e.g. vertical total electron content (VTEC), column [O/N2] ratio, F2-layer maximum electron density ( $\mathrm{NmF} 2$ ), F2 region maximum electron density height ( $\mathrm{hmF} 2$ ) and magnetic data. By employing signal analysis, they reported existence of short-period oscillations (DP2) as well as diurnal and semi-diurnal fluctuations (Ddyn) in the geomagnetic field.

Astafyeva (2009) investigated the effect of strong southward directed IMF $B_{z}$ on the ionosphere electron density using total electron content (TEC) data from different satellite missions, and reported a dayside enhancement in the ionization as caused by a super fountain effect. Bagiya et al. (2014) studied the ionosphere response to the geomagnetic storm of July 2012 for which $B_{z}$ turned southward for a long time. They observed positive (negative) storm effects during the main (recovery) phase and also pointed a hemispherical asymmetry in TEC variations. Astafyeva et al. (2017) studied the response of ionosphere- 
thermosphere during the magnetic storm of 21-23 June 2015 and concluded that the main driver of TEC variations is PPEF and DDEF during the main and recovery phases, respectively. Most of previous studies on $D_{\text {dyn }}$ as done by Fathy et al.(2014), Nava et al.(2016), Zulaga et al. (2016), Zaourar et al. (2017) and Kashcheyev et al. (2018) were focused on low latitude or in a particular region.

In the present article, we have focused on the ionosphere response to space weather event of 25-29 August 2018 by using VTEC maps, global and regional electron contents, [O/N2] ratio, $\mathrm{NmF2}$ and magnetic field variations. In this regard, the ionospheric and magnetic signatures have been presented at low- and mid-latitudes. Through this work, we have emphasized the role PRC in determination of ionospheric currents, effect of thermospheric winds at different longitudinal sectors and extended the evaluation of $D_{\text {iono }}$ at mid latitudes. The rest of the article is organized as follows: Section 2 describes the different data sets and processing tools used in our study. The section 3 describes geomagnetic activity during 2529 August 2018. The resultant observations are presented in Section 4 and Section 5 is devoted to discussion on the ionospheric and magnetic signatures by comparing the results with theoretical models and finally we conclude the paper in Section 6.

\section{Data sets and data processing}

\subsection{Data sets}

We have used the following data sets for our analysis:

- Solar wind parameters, namely z-component of Interplanetary Magnetic Field $\left(B_{z}\right)$ and solar wind speed $V_{s w}$ are provided by ACE satellite, http://omniweb.gsfc.nasa.gov/.

- The geomagnetic indices, used for storm characterization, are obtained from world data center (WDC), http://wdc.kugi.kyoto-u.ac.jp). The development and decay of ring current is estimated by high-resolution (1-minute) SYM-H index [Wanliss \& Showalter, 2006]. The partial ring current (PRC), play a key role in the generation of the disturbance field [Fukushima \& Kamide, 1973], and is measured by ASYM-H index [Weygand \& McPherron, 2006] .

- Polar cap (PC) indices are used to estimate the energy transmitted to the magnetosphere during the geomagnetic storm [Stauning et al., 2008]. 
- Global ionosphere maps (GIMs), namely UPC Quarter an hour Rapid GIM (UQRG) are provided by Universitat Politecnica de Catalunya (UPC). These maps are used to compute the global and regional electron contents. The GIMs contain VTEC data in standard ionosphere map exchange (IONEX) format for the entire globe with a spatial resolution of $2.5^{\circ}$ in latitude and $5^{\circ}$ in longitude and temporal resolution is 15 minutes, thus each map contains 5,184 data points (called GIM cells).

- The variations in the Earth's magnetic field are recorded by the observatories of the INTERMAGNET network, http://intermagnet.org.

- To understand the variations in neutral constituents, we have analyzed the data of thermospheric column [O/N2] ratio provided by Global Ultraviolet Imager (GUVI) spectrograph of the TIMED satellite, http://guvitimed.jhuapl.edu/.

- The ionosondes data has been taken by GIRO DIDBase, http://umlcar.uml.edu/. Automatic and manually scaled data of foF 2 has been used to compute the $\mathrm{NmF} 2$ [Rishbeth, 1989].

Figure 1 shows the locations of GNSS receivers (red), magnetic observatories (green) and ionosondes (blue) at low and mid-latitudes in three longitudinal sectors. The geographic coordinates of the considered GNSS and ionosonde stations are presented in tables 1 and 2, respectively. Table 3 depicts the geographic coordinates of the considered magnetic observatories.

\subsection{Data processing}

\subsubsection{GPS data}

The slant total electron content (STEC) for a single receiver is taken from the global positioning system (GPS) observations, ftp://cddis.nasa.gov/gnss/data. In this regard, the raw GPS measurements are calibrated by a debiasing technique [Ciraolo et al., 2006], where the least square estimation is applied to evaluate VTEC from corresponding sTEC values.

\subsubsection{GEC and REC}

To understand the global and regional variations in electron density, as affected by a geomagnetic activity, the global electron content (GEC) and regional electron content (REC) have been evaluated. Here, GEC is the number of electrons in a sphere of radius $R_{E}+450 \mathrm{~km}$ and is measured in the unit of GECU where $1 G E C U=10^{26}$ electrons. The GEC is calculated by 
multiplying VTEC value of each GIM cell $T_{p, q}$ with the corresponding area $A_{p, q}$ and summing over the entire globe [Afraimovich et al., 2006], i.e.

$$
G E C=\sum_{p, q} T_{p, q} A_{p, q}(1)
$$

Here $p$ and $q$ denote, respectively the latitude and longitude of a GIM cell. For evaluation of the regional variations, GEC has been subdivided into four longitudinal regions, namely Asia $\left(60^{\circ}: 150^{\circ} \mathrm{E}\right)$, Africa $\left(-30^{\circ}: 60^{\circ} \mathrm{E}\right)$, America $\left(-120^{\circ}:-30^{\circ} \mathrm{E}\right)$ and Pacific $\left(-180^{\circ}:-120^{\circ} \mathrm{E}, 150^{\circ}: 180^{\circ}\right.$ E). The electron content in each sector represents the corresponding REC index and is calculated in the same manner as GEC in Eq. (1).

\subsubsection{Magnetometer data processing}

The horizontal component of geomagnetic field, during the storm, can be written as a superposition [Le Huy \& Amory-Mazaudier, 2005; Nava et al., 2016; Kashcheyev et al., 2018]

$$
H=H_{o}+S_{R}^{H}+D_{m a g}+D_{\text {iono }}
$$

Here $H_{O}$ indicates the magnetic field generated by the Earth's core. $S_{R}^{H}$ presents regular diurnal fluctuations in magnetic field and is computed by taking the average of the variations over five quiet days $S_{q}$ [Chapman \& Bartels, 1940]. In Eq. (2), $D_{m a g}$ and $D_{\text {iono }}$ are the magnetic disturbances associated with magnetospheric and ionospheric currents, respectively [Cole, 1966; Fukushima and Kamide, 1973]. The former is produced mainly by the ring current, which is composed of symmetric part (Sugiura \& Kamei, 1991; Wanliss \& Showalter, 2006) and an asymmetric part, i.e. the PRC (Cummings, 1966). Two magnetic indices, namely SYMH and ASYMH provide, respectively an estimate of symmetric and antisymmetric part of the ring current. The $D_{\text {iono }}$ can be computed as

$$
D_{\text {iono }}=H-H_{o}-S Y M H \cdot \cos (\phi)-S_{q}
$$

where $\phi$ refers to the geomagnetic dip latitude. At low-latitudes, the ionospheric currents flow in the E region on the dayside, thus Eq. (3) which uses symmetric part of the ring current (SYMH index) is applicable only on the dayside, where there are sufficient 
conductivities in the dynamo region $(90-150 \mathrm{~km})$. This simple expression for $D_{\text {iono }}$ in Eq. (3) is valid at mid-and low-latitudes, because in the auroral zone there exist additional magnetic disturbances associated with other ionospheric currents (Stauning 2012; Zaourar et al., 2017), however, that subject is outside the scope of this study. At the equator the disturbed ionospheric currents have two major components, i.e. DP2 and $D_{d y n}$ (AmoryMazaudier et al., 2018, Le Huy \& Amory-Mazaudier, 2005, Nishida, 1968), which are related to two large-scale mechanisms, PPEF and DDEF [Vasyliunas, 1970; Blanc \& Richmond, 1980). Hence, we can write the corresponding relation in the form

$$
D_{\text {iono }}=D P 2+D_{d y n}
$$

To find the period of magnetic oscillations as generated by ionospheric disturbance, we may apply low/high pass filters to $D^{\prime}$ iono which is given by

$$
D^{\prime}{ }_{\text {iono }}=D_{\text {iono }}-A S Y M H \cdot \cos (\phi)
$$

It is known that PRC causes the disturbance fields on the nightside and early morning [Takahashi et al., 1991]. Hence, for an accurate evaluation of ionospheric disturbance, the effects of such currents are subtracted as depicted in Eq. (5).

\section{Geomagnetic activity during 25-29 August 2018}

On 20 August 2018, a coronal mass ejection (CME) has blown off towards the Earth and struck its magnetosphere on the $25^{\text {th }}$ of the same month. This slowly moving CME was expected to cause a minor geomagnetic activity as predicted by National Oceanic and Atmospheric Administration (NOAA) scientists. However, it took a long time to shift IMF's zcomponent southwards from August 25 15:55 UT to 26 August 09:45 UT, thus it allowed a large number of energetic particles to enter the Earth's atmosphere and resulted in a severe (G4) geomagnetic storm. Figure 2 shows various global parameters for the period 23 August to 01 September 2018: the first panel illustrates the z-component of IMF in nanotesla (nT) and the second panel depicts the solar wind speed in $\mathrm{km} / \mathrm{s}$, in third and fourth panels we show, respectively the SYM-H index in $\mathrm{nT}$ and the $\mathrm{PC}$ indices in $\mathrm{mV} / \mathrm{m}$. The fifth panel represents the GEC in GECU. Additionally, we have drawn vertical lines to depict the start of 
the compression phase (CP) on 25 August at 07:30 UT, main phase (MP) on 25 August at 17:06, recovery phase (RP) on 26 August at 07:11 UT and high-speed solar wind streams (HSSWs) on 26 August at 17:32 UT and on 27 August at 16:00 UT, respectively. It reveal that the $\mathrm{CP}$ of the storm has lasted for almost 10 hours, the $\mathrm{B}_{z}$ turned southward at the start of MP and remained there till 09:42 UT of the next day, thus allowing large particle flux to penetrate the Earth's magnetosphere. Consequently, the SYM-H index began to decrease indicating the start of MP. It reaches a minimum value of -207 nT at 07:11 UT on 26 August, generating G4 geomagnetic conditions. Afterward, the z-component of IMF begin to fluctuate. During the RP, solar wind speed has increased and reached a maximum value of $600 \mathrm{~km} / \mathrm{s}$ during the late hours of August 27. The PC indices show a large increase during the period of southward directed $B_{2}$.

\section{Results}

\subsection{The global context and GEC}

The GEC exhibit a strong peak followed by two small peaks, while solar radio flux remains approximately constant during this period, and thus the variations in GEC cannot be related to it. However, large energy inputs from the solar wind to magnetosphere, as indicated by PC index (Troshichev et al., 2014), are possible sources of the enhancement in GEC. In order to investigate the regional contribution to the observed peaks in GEC, we have plotted $\triangle \mathrm{REC}$ for Asian, African, American and Pacific regions, as shown in Figure 3. Each curve shows the difference between REC of a region and its daily quite value, which is calculated by using three quite days before the storm with AP index $<22 \mathrm{nT}$. The central and bottom plots in Figure 3 show, respectively the $\triangle G E C$ and SYM-H index for a period 23 August-01 September. The $\triangle R E C$ indicates that the Pacific sector responded first as depicted by the increased value of REC, followed respectively by America, Asia and Africa. In this regard, the largest enhancement has been observed in Asian sector. A decrease in REC begun on 26 August 00:00 UT in the American region, followed by Pacific, Asia and African sectors, where the largest decrease in REC is noted for the American sector. The second peak is initially found in Asian followed by African and American sectors, while Pacific sector has no significant contribution to this peak. The largest increase during the second peak is found to be in American sector. The GEC plot in Figure 3 highlights fluctuations during MP of the storm, which is mainly contributed by the Pacific sector as indicated in corresponding REC 
plots. Figure 4 represents $\triangle V T E C$, extracted from GIMs, as a function of latitude and time at fixed longitudes corresponding to four sectors: (from top to bottom) Asia ( $\left.110^{\circ} \mathrm{E}\right)$, Africa($\left.10^{\circ} \mathrm{E}\right)$, America $\left(-70^{\circ} \mathrm{E}\right)$ and Pacific $\left(-150^{\circ} \mathrm{E}\right)$. All the four sectors have depicted positive storm effects on the day of storm with respect to average of three magnetic quiet days prior to storm. However, we note the following substantial differences:

- Asian sector shows large enhancement in VTEC on the storm day (August 26).

- African sector indicates a small positive ionospheric storm in the northern hemisphere during the MP and a large positive storm in the southern hemisphere in RP. Whereas, negative storm effects are observed in the northern hemisphere during RP.

- American sector exhibits positive (negative) storm effects in the northern hemisphere during the main (recovery) phase. We also observe an enhancement of TEC in the southern hemisphere during RP that lasted for two days after the storm.

- The Pacific sector shows a strong increase in VTEC in the MP and, in the northern hemisphere, negative storm effect during RP.

Figure 5a presents [O/N2] ratio as obtained from Global Ultraviolet Imager (GUVI) the spectrograph of the TIMED satellite. The maps are presented for four days: 25 August (before the storm), 26 August (the day of the storm) and the next two days. The polar regions of both hemispheres have shown a decrease in [O/N2] on the storm day (26 August). However, there is an asymmetric increase in the density ratio [O/N2] at low- and mid-latitudes on the day of the storm. The northern mid-latitude regions of American and Pacific sectors show enhancement in $[\mathrm{O} / \mathrm{N} 2]$ ratio, whereas southern mid-latitudes of the Asian sector show an increase on the same day. In Figure 5b, we have compared the response of both hemispheres regarding the variations in the [O/N2] ratio by presenting the time evolution of [O/N2] ratio with levels $>0.5$. In this regard, the northern hemisphere (solid red line) shows a relatively large decrease as compared to the southern hemisphere (blue dotted line) during late hours of 26 August. The maximum decrease in O/N2 ratio is observed about 30 hours after MP and 16 hours after RP. On 26 august between 17-23 UT, O/N2 ratio drops about 20 percent of its quite time values in northern hemisphere.

\subsection{Low and middle latitudes VTEC and NmF2 variations}

Figure 6 presents the VTEC variations as recorded by GPS stations. Each panel shows VTEC 
(in red) with an average daily value (in blue) superimposed. The averaged value is computed by taking the mean over three geomagnetic quiet days prior to the storm day having $\mathrm{Kp}<3^{-}$ (Nava et al, 2016: Kashcheyev et al, 2018). The first to third panels correspond to stations in the Asian sector, namely HKSL, JOG2, and YAR2. The northern mid-latitude (HKSL) and lowlatitude (JOG2) stations show enhancement in VTEC on the storm day that has lasted for the next two days, whereas the southern mid-latitude station (YAR2) has not recorded any VTEC variation. Next three panels in Figure 6 correspond to the African sector, the northern midlatitude station (NOT1) shows no enhancement during the storm period while southern midlatitude station (WIND) exhibits an increase in VTEC value on the storm day. The lowlatitude station (NKLG) depicts enhancement in VTEC lasting until the end of August. Seventh to ninth panels in the same figure present American sector comprising of BRMU, MGUE and RIOP stations. The BRMU (northern mid-latitude) shows a small increase on the storm day followed by negative storm effects. The MGUE (southern mid-latitude) exhibits doubly humped increase in VTEC not only on storm day but also on the next day, however at low-latitude station (RIOP) there is no change in VTEC. Further detail about percentage increase/decrease in VTEC at individual GPS stations is provided in table 4.

In Figure 7a we present variations in NmF2 from 23 August to 02 September 2018 for three ionosondes of the Asian region. All the ionosondes have shown an increase in NmF2 on 26 August. The northern mid-latitude (JJ433), equatorial (GUS13) and southern mid-latitude station (BR52P) show an increase in $\mathrm{NmF2}$ by $57 \%, 75 \%$ and $36 \%$, respectively. Figure $7 \mathrm{~b}$ depicts the NmF2 parameter for three ionosondes of the African region. Northern midlatitude station (AT138) has shown 73\% decrease in NmF2 on 26 August while in the equatorial station (ASOOQ) there is an enhancement in NmF2 that lasted till 29 August. We observe an enhancement of 120\%,100\%, 220\% and 210\%, respectively, on 26, 27, 28 and 29 of August 2018. The southern mid-latitude station shows no significant variation during this period. Figure 7c presents $\mathrm{NmF2}$ measurements recorded by three ionosondes located in the American region. Northern mid-latitude station (PRJ18) shows a large decrease (54\%) in $\mathrm{NmF2}$ on 26 August while in the equatorial station (SAAOK) there is no significant variation during the considered period. Southern mid-latitude station (PSJ5J) shows an enhancement in NmF2 by $93 \%$ and $120 \%$ on 26 and 27 August, respectively.

\subsection{Earth's magnetic field variations at low and mid-latitudes}


The first to third panels in Figure 8a present the variations in H-component of the Earth's magnetic field (black), its quiet daily variation $S_{q}$ (blue) and magnetic disturbances due to ionospheric electric current $D_{\text {iono }}$ (red), as recorded by low-latitude observatories GUA, TAM, and KOU. The fourth and fifth panels show the ASYM-H and SYM-H indices and vertical lines correspond, respectively to $\mathrm{CP}, \mathrm{MP}, \mathrm{RP}$, and the arrival of the HSSWs. All the considered stations highlight degradation in the $\mathrm{H}$-component of the geomagnetic field, which is the characteristic of a typical magnetic storm. Various features as observed at the three stations are summarized as follows:

- The largest disturbance of the H-component is observed at GUA on 26 August at 07:33 UT having a value $-233 \mathrm{nT}$. At TAM station the amplitude of the disturbance is found to be $-151.5 \mathrm{nT}$ on 26 August at 16:24 and at KOU the corresponding value is 123.3 $\mathrm{nT}$ on 26 August 04:24 UT. We also note that at the beginning of storm GUA is on the dayside, whereas TAM and KOU are on the nightside.

- The anti-Sq signature of $D_{\text {iono }}$ during the RP can be well-identified at TAM and KOU stations. A storm wind produced by auroral Joule heating does not exhibit a uniform planetary extension and mainly affects the African and American sectors.

- The $D_{\text {iono }}$ becomes positive having large values during the MP at the nightside stations, namely KOU and TAM. These positive values are the signature of ASYM-H.

- The multiple peaks, not observed in typical H plots, are observed at KOU and TAM stations during the RP.

In Figure 8b, first to third panels are the same as in Figure 10 for northern mid-latitude stations. In the top panel, the BMT (Asian sector) exhibits the largest decrease in $\mathrm{H}$ component of the geomagnetic field having a magnitude -195.1 nT on 26 August 07:44 UT as compared to $-148.2 \mathrm{nT}$ 07:07 UT at CLF and $-150 \mathrm{nT}$ at SBL. The CLF and SBL stations exhibit large positive values of Diono which can be associated with the ASYM-H index. Figure $8 \mathrm{c}$ presents the analysis for southern mid-latitudes stations, namely GNG (Asia), HER (Africa) and PIL (America). The GNG shows the largest decrease in $\mathrm{H}$ during the MP of the storm, while HER and PIL depict large positive values of Diono in the MP.

Using spectral analysis on $\mathrm{D}^{\prime}$ iono, we have separated different magnetic oscillations corresponding to various physical processes. Figure 9a shows, from top to bottom, the $B_{z}$ 
component of IMF, magnetic disturbance (period<4hours) at Asian, African and American low-latitude stations. The magnetic oscillations are observed simultaneously at all stations having different strengths - during the period of southward directed $B_{z}$. These oscillations may be related to DP2 perturbations due to PPEF.

The difference in the strength of oscillations in Asian and American sectors can be used to analyze the effect PPEF on dayside and nightside sectors. By using an infinite impulse response (iir) band-pass filter with stop-band attenuation $60 \mathrm{~dB}$ and transition band steepness 0.85 , we have separated the diurnal perturbations having period between 18-30 hours corresponding to Ddyn [Nava et al 2016, Bulusu et al 2018] as shown in Figure 9b for low-latitude stations. These oscillations are associated with Ddyn. One common feature at all stations is the increase in the strength of diurnal oscillations during the main phase and decay during the several days after the storm. Diurnal oscillations start first at America, followed by Asia and Africa. The largest amplitude of such oscillations is also found in the Asian sector.

\section{Discussion}

\section{1 lonospheric signatures}

This section is devoted to the interpretations of the observed ionospheric results based on various models. A slow-moving CME hits the Earth's magnetosphere on 25 August around 07:30 UT, followed by the long compression phase of small amplitude $\sim 30 \mathrm{nT}$ lasting for $\sim 10$ hours, and the main phase of the storm has started at 17:06 UT. The GEC exhibits two strong peaks, first at 06:30 UT on 26 August having the amplitude of 0.265 GECU and second at 16:00 UT on 27 August with amplitude 0.084 GECU. The PC indices show two large periods of energy input from the solar wind to magnetosphere: first period (E1) starts on 25 August at 16:47 lasting for 35 hours and resulting in a major peak in GEC, the second period (E2) starts at 03:34 on 27 August and lasting until mid-night of the same day causing a minor peak in GEC. The REC plot shows that local dayside sectors (Pacific and American) responded earlier to the first peak of GEC. In this regard the Asian (American) sector exhibits the largest positive (negative) storm effect. At the start of the MP on August 25 at 17:06 UT, the American and Pacific sectors were on the dayside having local time $L T=17: 06-5=12: 06$ and $\mathrm{LT}=17: 06-7=10: 06$, respectively. For African region corresponding time was $\mathrm{LT} \sim \mathrm{UT}=$ 
17:06, i.e. an evening sector, whereas the Asian sector was on the nightside with $L T=17: 06+$ $07=24: 06$.

For the second peak (23:00 UT) in GEC, the Asian sector responded first followed by African and American regions, respectively. At this time, the Asian sector was on the morning side while America and Africa were, orderly on the evening and night sides. The observed results are in agreement with Fuller-Rowell et al., (1994) model, which predicts the largest response in nightside sectors. Figure 5 shows a hemispherical asymmetry at all the four sectors, whereas negative storm effects are observed in the northern hemisphere. In Figure 6 we note that the largest increase in VTEC at GPS stations located in the Asian sector $\left(1^{\text {st }}\right.$ to $3^{\text {rd }}$ panels). Moreover, a negative storm is observed in the northern mid-latitude stations of African and American sectors, which correspond well to the results of Figures 3 and 4 . The NmF2 measurements - observed by ionosondes - in three longitudinal sectors (Fig. 6a, b, c) show that largest positive increase is observed in Asian. While Northern mid-latitude stations of Africa (Fig. 6b) and America (Fig. 6c) have shown a decrease in NmF2 during the MP. Thus, both NmF2 and TEC have a positive correlation for the considered geomagnetic storm in agreement with the finding of Joshua et al. (2018). Previous studies shows that positive storm effect is caused by various mechanisms [Zhang et al.,2004: Goncharenko et al., 2007: Huang,2005:de Abreu et al.,2010: Yuan et al.,2015]. However, it has been proved that negative storm effect is primarily caused by O/N2 ratio decrease [Prölss \& Werner, 2002: Korenkov et al.,2012]. The fact that negative ionospheric storm, as observed by TEC and $\mathrm{NmF2}$ data, is found in the summer hemisphere only, which can be explained by the theoretical model of Fuller-Rowell (1996) that predicts negative storm in summer hemisphere (northern hemisphere in the present case). Indeed, outside periods of geomagnetic storms the thermospheric winds flow from summer to winter hemisphere. During periods of geomagnetic activity the storm wind - due to Joule heating in the auroral zone - flows from the pole towards the equator, this storm wind disturbs the regular circulation. The storm causes changes in neutrals composition: increase in atomic oxygen and decrease in molecular nitrogen in winter hemisphere which decreases recombination rate and increases electron density, thus creating a positive ionospheric storm effects in the winter hemisphere. In the summer hemisphere, there is a decrease in atomic oxygen and increase in molecular nitrogen that enhances the recombination rate and resulting in 
negative ionospheric storms [Prölss, 1980: Prölss, 1995: Förster et al., 1999: Forbes, 2007]. It is further confirmed by Figure 5b, which shows that there is a large decrease in [O/N2] ratio in the northern hemisphere during late hours of 26 August, at the same time when we see a decrease in TEC and NmF2 in the northern hemisphere. Hence, this negative storm effect can be associated with neutral composition changes as caused by thermospheric winds generated due to Joule heating at polar regions [Rishbeth, 1998]. However, these composition changes as caused by thermospheric winds, do not have same effect at all longitudes, e.g. no negative storm effect is found at Asian sector in TEC as well as in NmF2. The intensity and duration of observed negative storm effect as indicated by Figure 5 is maximum in dayside sectors (America and pacific in the present case). The depletion in TEC (caused by $\mathrm{O} / \mathrm{N} 2$ ratio) first appears in African sector followed by American and Pacific sector. This indicates that oxygen depletd and nitrogen rich winds generated due to joule heating at upper atmosphere corotates with earth [Fuller-Rowell et al., 1996: Zhang et al., 2002].

In addition, to the thermal expansion of the atmosphere, two other large scale physical processes (PPEF and DDEF) affect the dynamics of the ionosphere during magnetic storms and can alter the ionization distribution. The magnetic signature of PPEF mechanism was brought to light by Nishida (1968) and the first theory was formulated by Vasyliunas (1970). During the PPEF a magnetospheric convection electric field affects all latitudes almost instantaneously, which has been observed not only in the ionospheric data but also in magnetic variations [Nishida, 1968]. One may see the influence of PPEF on VTEC, when we observe simultaneous peaks of VTEC at various latitudes in the different longitudes sectors (see Figure of Nava et al., 2016). However, in our case study there is no such observation at all the considered latitudes. The second mechanism, i.e. DDEF was theorized by Blanc \& Richmond (1980). A dissipation of Joule energy in the auroral zone, during magnetic storms, produces a disturbed circulation of thermospheric winds between the auroral zone and the equator. These storm winds generate disturbed currents and electric fields that affect the ionization of the ionosphere. Fejer [1983] highlighted the electric field disturbance due to DDEF and Sastri [1988] showed that this mechanism produces degradation in ionization on the second day of a storm. However it is difficult, when analyzing the VTEC that integrates 
the ionization all the way between the satellite and the GPS receiver, to separate the effects of different mechanisms contributing to the ionization.

\subsection{Magnetic signatures}

The observations of Earth's magnetic field at the mid- and low-latitudes make it possible to recognize the different systems of large-scale ionospheric electric currents during a geomagnetic storm. The magnetic disturbances related to such currents are DP2 and Ddyn associated, respectively with the PPEF and DDEF. The former disturbance, namely DP2 has been known since 1968 (Nishida et al., 1968), whereas Ddyn was introduced by Le Huy and Amory-Mazaudier in 2005 for simple cases of post-storm magnetic quiet days, during which the auroral electric currents are zero. The DP2 has short-term fluctuations of less than 2 to 3 hours while the Ddyn perturbation has longer diurnal and semi-diurnal variations. During the geomagnetic storms, large energy inputs and moment transfer at high-latitude perturb the normal circulation of thermospheric winds. This results in the westward electric field on the day-side and eastward on the night-side [Blanc and Richmond, 1980; Fuller-Rowell et al.2002]. As these electric fields are opposite to their normal (quite day) orientation, we observe an anti-sq signature at low and mid latitudes in the magnetic data during the recovery phase of storms [Le Huy and Amory-Mazaudier 2005; Zaka et al. 2009; Yamazaki and Kosch 2015]. In this section, we investigate the strength of anti-sq signatures at low-mid latitude and role of PRC on the ionospheric disturbance currents.

A large positive value of Diono at low-latitude stations (nightside), i.e. TAM and KOU can be associated with PRC as indicated by the ASYM-H index in Figure 8a. The anti-sq signatures of Diono are well-identified at local dayside stations TAM and KOU, as proposed by Blanc \& Richmond (1980). During MP and RP, northern mid-latitude stations show longitudinal asymmetry in the H-component and Diono (Figure 8b). However, there is no clear anti-sq signature identified during the days after the storm. The southern mid-latitude stations, namely HER and PIL which are at local morning dayside, also exhibit a large positive value of Diono and is associated with PRC (ASYM-H index). The three stations in the Asian sector GUAM (Fig. 8a), BMT (Fig. 8b) and GNG (Fig. 8c) do not show a positive variation of Diono because they are located on the dayside (when ASYM-H is minimum) and therefore are not

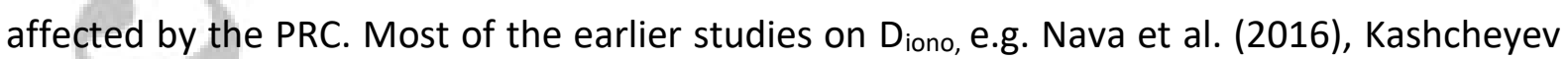
et al. (2018) and Bulusu et al. (2018) did not take into account the effect of PRC in determination of $D_{\text {iono. }}$ A large positive value of $D_{\text {iono }}$ during the main phase of a storm is the effect associated with PRC and this can influence the evaluation - through various filters techniques - of magnetic signatures of PPEF and DDEF. To account for only ionospheric 
currents, we have defined $D^{\prime}$ iono and applied filters on it to estimate magnetic effect of PPEF and DDEF. As above mentioned references considered different magnetic storms, so a direct comparison cannot be made, but a possible error in the estimation of PPEF and DDEF is expected if $D_{\text {iono }}$ is not modified to $\mathrm{D}^{\prime}$ iono. The anti-Sq circulation, predicted by the BlancRichmond model, is observed (Figure 8a) during several days of the RP mainly at TAM and KOU stations which are located closer to the equator. These two stations are on the nightside during the main phase (17:06 UT 25 $5^{\text {th }}$ August to 07:11 UT 26 ${ }^{\text {th }}$ August) of the considered storm. The fact that mid-latitude stations do not show the dayside anti-Sq trend in Diono variations (Figures $8 \mathrm{~b}$ and $8 \mathrm{c}$ ) may imply that they can be located on a focus of one of the electric current cells, which are predicted by the Blanc-Richmond model (1980). These cells are represented in Figure 8 of the article by Mazaudier \& Venkateswaran (1990). This study suggests that further work should be done to generate anti-Sq current vectors by taking data of large a number of magnetic observatories during magnetic storms.

To investigate the DP2 perturbations we have employed a high pass filter to separate the magnetic disturbances having period ? 04 hours (Figure 9a). Such perturbations penetrate simultaneously at all longitudinal sectors and follow the same trend as $B_{z}$ oscillations [Kikuchi et al., 1996]. However, the short period observed oscillations which are not simultaneous may be associated with local noise at the respective station [Khomutov et al, 2017]. The process of penetration of the magnetospheric convection electric field varies with longitude, in this regard Fejer et al., 2008 established a model of PPEF based on ROCSAT satellite measurements. Kashcheyev et al. 2018, have showed the difference in PPEF response as a function of longitude at the beginning of a magnetic storm. Different authors have studied the latitudinal profiles of PPEF in a given longitude sector (Mazaudier et al., 1984, Kikuchi et al., 2000; Kobea et al., 2000; Mene et al., 2011). The diurnal oscillations having period between 16-28 hours - which can be associated with Ddyn are extracted using a bandpass filter. The temporal difference in the observed Ddyn at different longitudinal sectors, as seen in Figure 9b, might be due to the local time differences. Further, the Ddyn oscillations have different observation span at various longitudinal sectors, which is consistent with the findings of Fathy et al. (2014) and Nava et al. (2016).

\section{Conclusion}

To conclude, we have studied the space weather event of 25-29 August 2018 by using various data sets. The main ionospheric and magnetic features are summarized as follows:

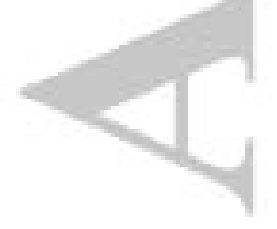


1. Positive storm effects are observed, first in the Pacific region followed, respectively by American, Asian, and African regions. This trend can be explained by the fact that the sectors on the local dayside (at the beginning of the considered storm) responded earlier.

2. The largest positive increase is observed in the Asian sector, which was at the local nightside. This finding is consistent with the simulations of Fuller-Rowell (1994).

3. Negative storm effects in VTEC are found only in the northern hemisphere and is consistent with the theoretical model of Fuller-Rowell (1996), which predicts that negative storm effects are dominant in the summer hemisphere (northern hemisphere in our case).

4. Thermospheric winds, generated due to Joule heating at polar regions, causes composition changes and is the primary cause of the observed negative storm effect.

5. The REC, TEC and NmF2 measurements show negative storm effects only in American (Noon side) and African (Evening side) sectors.

6. Storm time generated wind do not have the same planetary extension, (consequently the Asian sector has not shown negative storm effects) as observed in TEC and NmF2 data.

7. The analysis of magnetic data at low and mid-latitudes show a longitudinal asymmetry in the variations of magnetic field. However, investigations of midlatitude stations depict that the response of both hemispheres is almost symmetric.

8. The anti-sq signature, which is a key indicator of Ddyn, generated by ionosphere disturbance dynamo currents, is well identified at the low-latitude stations which were at the nightside during the main phase.

9. Mid-latitude stations of both hemispheres have not shown any well-identified signature of anti-Sq circulation during the recovery phase, it can be due to the fact that these stations are located on the focus of an electric current cell as suggested by Blanc and Richmond (1980).

10. It has been found that the response of both hemispheres is symmetric with respect to magnetic variations.

11. By using filter techniques, we have separated DP2 oscillations which occur simultaneously at all longitudes and follows the same trend as the $B_{z}$ oscillations. 
Regarding the ionospheric response to the geomagnetic storm we have observed the wellexplained, mainly by the Fuller- Rowell et al., $(1994,1996)$, signatures regarding the importance of local time and season at a given location.

Concerning the magnetic signature the study suggests that, for a better description of the ionospheric signature, the partial ring current as estimated by the ASYM-H magnetic index must also be taken into account along with the SYM-H index. Indeed, the magnetic variations at the nightside stations show the influence of PRC. Moreover, the investigation of disturbance dynamo at mid-latitudes suggests the existence of several electric current cells as modeled by Blanc and Richmond's (1980). It is therefore important to develop statistical studies of magnetic disturbance as generated by the ionospheric dynamo on a planetary scale.

\section{Acknowledgement}

The authors are thankful to the IGS Community for providing GNSS data, OMNI web data center (http://omniweb.gsfc.nasa.gov/) for making available solar wind parameters and geomagnetic activity indices, GIRODidbase (http://umlcar.uml.edu/) for providing ionosondes data, the Universitat Politecnica de Catalunya (UPC-IonSAT) and INTERMAGNET (http://intermagnet.org) for providing the VTEC data and magnetic data, respectively. This research work was partly supported by the HEC Pakistan: GrantNo.7632/Federal/NRPU/RD/HEC/2017. 


\section{References}

Afraimovich, E. L., Astafyeva, E. I., \& Zhivetiev, I. V. (2006). Solar activity and global electron content. Doklady Earth Sciences, 409(2), 921-924. https://doi.org/10.1134/s1028334x06060195

Amory-Mazaudier, C., Bolaji, O. S., \& Doumbia, V. (2017). On the historical origins of the CEJ, DP2, and Ddyn current systems and their roles in the predictions of ionospheric responses to geomagnetic storms at equatorial latitudes. Journal of Geophysical Research: Space Physics, 122(7), 7827-7833. https://doi.org/10.1002/2017ja024132

Astafyeva, E. (2009). Effects of strong IMF Bz southward events on the equatorial and mid-latitude ionosphere. Annales Geophysicae, 27(3), 1175-1187. https://doi.org/10.5194/angeo-27-1175$\underline{2009}$

Astafyeva, E., Zakharenkova, I., Huba, J. D., Doornbos, E., \& van den IJssel, J. (2017). Global lonospheric and Thermospheric Effects of the June 2015 Geomagnetic Disturbances: Multi-Instrumental Observations and Modeling. Journal of Geophysical Research: Space Physics, 122(11), 11,71611,742. https://doi.org/10.1002/2017ja024174

Bagiya, M. S., Hazarika, R., Laskar, F. I., Sunda, S., Gurubaran, S., Chakrabarty, D., Bhuyan, P.K., Sridharan, R., Veenadhari, B., \& Pallamraju, D. (2014). Effects of prolonged southward interplanetary magnetic field on low-latitude ionospheric electron density. Journal of Geophysical Research: Space Physics, 119(7), 5764-5776. https://doi.org/10.1002/2014ja020156

Blanc, M., \& Richmond, A. D. (1980). The ionospheric disturbance dynamo. Journal of Geophysical Research, 85(A4), 1669. https://doi.org/10.1029/ja085ia04p01669

Bulusu, J., R. K., A., Arora, K.,Chandrasekhar, N. P., \& Nagarajan, N.(2018). Effect of disturbance electric fields on equatorial electrojet over Indian longitudes. Journal of Geophysical Research: Space Physics, 123. https://doi.org/10.1029/2018JA025247

Ciraolo, L., Azpilicueta, F., Brunini, C., Meza, A., \& Radicella, S. M. (2006). Calibration errors on experimental slant total electron content (TEC) determined with GPS. Journal of Geodesy, 81(2), 111-120. https://doi.org/10.1007/s00190-006-0093-1

Chapman, S., \& J. Bartels (1940), Geomagnetism, Oxford University Press, New York. 
Cole, K. D. (1966). Magnetic storms and associated phenomena. Space Science Reviews, 5(6). https://doi.org/10.1007/bf00173103.

Cummings, W. D. (1966). Asymmetric ring currents and the low-latitude disturbance daily variation. Journal of Geophysical Research, 71(19), 4495-4503. https://doi.org/10.1029/jz071i019p04495

de Abreu, A. J., Fagundes, P. R., Sahai, Y., de Jesus, R., Bittencourt, J. A., Brunini, C., et al. (2010). Hemispheric asymmetries in the ionospheric response observed in the American sector during an intense geomagnetic storm. Journal of Geophysical Research: Space Physics, 115(A12), n/a-n/a. https://doi.org/10.1029/2010ja015661

Fathy, I., Amory-Mazaudier, C., Fathy, A., Mahrous, A. M., Yumoto, \& Ghamry, E. (2014). Ionospheric disturbance dynamo associated to a coronal hole: Case study of 5-10 April 2010, J. Geophys. Res. Space Physics, 119, 4120-4133, https://doi.org/10.1002/2013JA019510

Fejer, B. G., Larsen, M. F., \& Farley, D. T. (1983). Equatorial disturbance dynamo electric fields. Geophysical Research Letters, 10(7), 537-540. https://doi.org/10.1029/gl010i007p00537

Fejer, B. G., Blanc, M., \& Richmond, A. D. (2016). Post-Storm Middle and Low-Latitude Ionospheric Electric Fields Effects. Space Science Reviews, 206(1-4), 407-429. https://doi.org/10.1007/s11214$\underline{016-0320-x}$

Fukushima, N., \& Kamide, Y. (1973). Partial ring current models for worldwide geomagnetic disturbances. Reviews of Geophysics, 11(4), 795. https://doi.org/10.1029/rg011i004p00795

Fuller-Rowell, T. J., Codrescu, M. V., Moffett, R. J., \& Quegan, S. (1994). Response of the thermosphere and ionosphere to geomagnetic storms. Journal of Geophysical Research, 99(A3), 3893. https://doi.org/10.1029/93ja02015

Fuller-Rowell, T. J., Codrescu, M. V., Rishbeth, H., Moffett, R. J., \& Quegan, S. (1996). On the seasonal response of the thermosphere and ionosphere to geomagnetic storms. Journal of Geophysical Research: Space Physics, 101(A2), 2343-2353. https://doi.org/10.1029/95ja01614

Fuller-Rowell, T. J., Millward, G. H., Richmond, A. D., \& Codrescu, M. V. (2002). Storm-time changes in the upper atmosphere at low latitudes. Journal of Atmospheric and Solar-Terrestrial Physics, 64(12-14), 1383-1391. https://doi.org/10.1016/s1364-6826(02)001013

Förster, M., Namgaladze, A. A., \& Yurik, R. Y. (1999). Thermospheric composition changes deduced from geomagnetic storm modeling. Geophysical Research Letters, 26(16), 2625-2628. https://doi.org/10.1029/1999gl900514

Forbes, J. M., Dynamics of the thermosphere,J. Meteor. Soc. Jpn.,85, 193-213, 2007.

Gonzalez, W. D., Joselyn, J. A., Kamide, Y., Kroehl, H. W., Rostoker, G., Tsurutani, B. T., \& Vasyliunas, V. M. (1994). What is a geomagnetic storm?. Journal of Geophysical Research, 99(A4), 5771-5792. https://doi.org/10.1029/93JA02867 
Goncharenko, L. P., Foster, J. C., Coster, A. J., Huang, C., Aponte, N., \& Paxton, L. J. (2007). Observations of a positive storm phase on September 10, 2005. Journal of Atmospheric and Solar-Terrestrial Physics, 69(10-11), 1253-1272. https://doi.org/10.1016/i.jastp.2006.09.011

Huang, C.-S. (2005). A strong positive phase of ionospheric storms observed by the Millstone Hill incoherent scatter radar and global GPS network. Journal of Geophysical Research, 110(A6). https://doi.org/10.1029/2004ja010865

Joshua, B. W., Adeniyi, J. O., Oladipo, O. A., Doherty, P. H., Adimula, I. A., Olawepo, A. O., \& Adebiyi, S. J. (2018). Simultaneous response of NmF2 and GPS-TEC to storm events at llorin. Advances in Space Research, 61(12), 2904-2913. https://doi.org/10.1016/j.asr.2018.03.031

Kikuchi, T., H. Lühr, T. Kitamura, O. Saka, and K. Schlegel (1996), Direct penetration of the polar electric field to the equator during a DP2 event as detected by the auroral and equatorial magnetometer chains and the EISCAT radar, J. Geophys. Res., 101, 17,161-17,173, doi:10.1029/96JA01299.

Kikuchi, T., Lühr, H., Schlegel, K., Tachihara, H., Shinohara, M., \& Kitamura, T.-I. (2000). Penetration of auroral electric fields to the equator during a substorm. Journal of Geophysical Research: Space Physics, 105(A10), 23251-23261. https://doi.org/10.1029/2000ja900016

Kobea, A. T., Richmond, A. D., Emery, B. A., Peymirat, C., Lühr, H., Moretto, T., et al. (2000). Electrodynamic coupling of high and low latitudes: Observations on May 27, 1993. Journal of Geophysical Research: Space Physics, 105(A10), 22979-22989. https://doi.org/10.1029/2000ja000058

Kashcheyev, A., Migoya-Orué, Y., Amory-Mazaudier, C., Fleury, R., Nava, B., Alazo-Cuartas, K., \& Radicella, S. M. (2018). Multivariable Comprehensive Analysis of Two Great Geomagnetic Storms of 2015. Journal of Geophysical Research: Space Physics, 123(6), 5000-5018. https://doi.org/10.1029/2017ja024900

Korenkov, Y. N., Klimenko, V. V., Klimenko, M. V., Bessarab, F. S., Korenkova, N. A., Ratovsky, K. G., et al. (2012). The global thermospheric and ionospheric response to the 2008 minor sudden stratospheric warming event. Journal of Geophysical Research: Space Physics, 117(A10), n/a-n/a. https://doi.org/10.1029/2012ja018018

Khomutov, S. Y., Mandrikova, O. V., Budilova, E. A., Arora, K., \& Manjula, L. (2017). Noise in raw data from magnetic observatories. Geoscientific Instrumentation, Methods and Data Systems, 6(2), 329-343. https://doi.org/10.5194/gi-6-329-2017

Le Huy, M. (2005). Magnetic signature of the ionospheric disturbance dynamo at equatorial latitudes: "Ddyn." Journal of Geophysical Research, 110(A10). https://doi.org/10.1029/2004ja010578

Mazaudier, C., Blanc, M., Nielsen, E., \& Zi, M.-Y. (1984). Latitudinal Profile of the Magnetospheric Convection Electric Field at Ionospheric Altitudes from a Chain of Magnetic and Radar Data. Journal of Geophysical Research, 89(A1), 375-381. https://doi.org/10.1029/ja089ia01p00375 
Mazaudier, C., \& S. V. Venkateswaran (1990), Delayed ionospheric effects of the geomagnetic storms of March 22, 1979, studied by the sixth coordinated data analysis workshop (CDAW6), Ann. Geophys., 8, 511- 518.

Mene, N.M., A. T. Kobéa, O. K. Obrou, K. Z. Zaka, K. Boka, C. Amory- Mazaudier and P. Assamoi (2011), Statistical study of the DP2 enhancement at the dayside dip-equator compared to low latitudes, Ann. Geophys. pp 2225-2233.

Migoya-Orue, Y. O., Azzouzi, I., Coïsson, P., Amory Mazaudier, C., Fleury, R., \& Radicella, S.M. (2016). lonospheric

and magnetic signatures of a high speed solar wind in low latitudes on 13 October 2012. Sun and Geosphere, 11(1),

23-35, ISSN 23678852

Nava, B., Rodríguez-Zuluaga, J., Alazo-Cuartas, K., Kashcheyev, A., Migoya-Orué, Y., Radicella, S. M., Amory-Mazaudier, C., \& Fleury, R. (2016). Middle- and low-latitude ionosphere response to 2015 St. Patrick's Day geomagnetic storm. Journal of Geophysical Research: Space Physics, 121(4), 34213438. https://doi.org/10.1002/2015ja022299

Nishida, A. (1968). Geomagnetic DP 2 fluctuations and associated magnetospheric phenomena. J. Geophys. Res., 73, 1795-1803, doi: 10.1029/JA073i005p01795.

Nishida, A., N. Iwasaki, and N. T. Nagata (1966). The origin of fluctuations in the equatorial electrojet: A new type of geomagnetic variation. Ann. Geophys., 22, 478-484.

Peymirat, C., Richmond, A. D., \& Kobea, A. T. (2000). Electrodynamic coupling of high and low latitudes: Simulations of shielding/overshielding effects. Journal of Geophysical Research: Space Physics, 105(A10), 22991-23003. https://doi.org/10.1029/2000ja000057

Prolss, G. W., Magnetic storm associated perturbations of the upper atmosphere: Recent results obtained by satellite-borne gas analyzers, Rev. Geophys.,18, 183, 1980.

Prölss, G. (1995), lonospheric F-region storms, in Handbook of Atmospheric Electrodynamics, vol. 2, edited by H. Volland, pp. 195-248, CRC Press, Boca Raton, Fla

Prölss, G. W., \& Werner, S. (2002). Vibrationally excited nitrogen and oxygen and the origin of negative ionospheric storms. Journal of Geophysical Research: Space Physics, 107(A2), IUA 5-1-IUA 5-12. https://doi.org/10.1029/2001ja900126

Rishbeth, H. (1989), Basic physics of the ionosphere, in Radio-Wave Propagation, edited by M. P. M. Hall and L. W. Barclay, pp. 75-94, Peter Peregrinus, London

Rishbeth, H. (1998). How the thermospheric circulation affects the ionospheric F2-layer. Journal of Atmospheric and Solar-Terrestrial Physics, 60(14), 1385-1402. https://doi.org/10.1016/s13646826(98)00062-5 
Rodríguez-Zuluaga, J., Radicella, S. M., Nava, B., Amory-Mazaudier, C., Mora-Páez, H., \& Alazo-Cuartas, K. (2016). Distinct responses of the low-latitude ionosphere to CME and HSSWS: The role of the IMF Bz oscillation frequency. Journal of Geophysical Research: Space Physics, 121(11), 11,528-11,548. https://doi.org/10.1002/2016ja022539

Sastri, J. H. (1988). Equatorial electric fields of ionospheric disturbance dynamo origin, Ann. Geophys., 6, 635- 642.

Stauning, P., Troshichev, O., \& Janzhura, A. (2008). The Polar Cap (PC) indices: Relations to solar wind parameters and global magnetic activity. Journal of Atmospheric and Solar-Terrestrial Physics, 70(18), 2246-2261. https://doi.org/10.1016/j.jastp.2008.09.028

Sugiura M., \& Kamei, T. (1991). Equatorial Dst index, IAGA Bulletin n²40, ISGI Pub. Office, Saint-Maurdes-Fossés.

Takahashi, S., Takeda, M., \& Yamada, Y. (1991). Simulation of storm-time partial ring current system and the dawn-dusk asymmetry of geomagnetic variation. Planetary and Space Science, 39(6), 821-832. https://doi.org/10.1016/0032-0633(91)90087-q

Troshichev, O. A., Podorozhkina, N. A., Sormakov, D. A., \& Janzhura, A. S. (2014). PC index as a proxy of the solar wind energy that entered into the magnetosphere: Development of magnetic substorms. Journal of Geophysical Research: Space Physics, 119(8), 6521-6540. https://doi.org/10.1002/2014ja019940

Vasyliunas, V. M. (1970), Mathematical models of magnetospheric convection and its coupling to the ionosphere, in Particles and Fields in the Magnetosphere, edited by M. McCormac, pp. 60- 71, Springer, New York.

Vasyliunas, V. M. (1972), The interrelationship of magnetospheric processes, in Earth's Magnetosphere Processes, edited by B. M. McCormac, pp. 29-38, D. Reidel, Norwell, Mass.

Weygand, J. M., \& McPherron, R. L. (2006). Dependence of ring current asymmetry on storm phase. Journal of Geophysical Research, 111(A11). https://doi.org/10.1029/2006ja011808

Wanliss, J. A., \& Showalter, K. M. (2006). High-resolution global storm index: Dst versus SYM-H. Journal of Geophysical Research, 111(A2). https://doi.org/10.1029/2005ja011034

Yamazaki, Y., \& Kosch, M. J. (2015). The equatorial electrojet during geomagnetic storms and substorms. Journal of Geophysical Research: Space Physics, 120(3), 2276-2287. https://doi.org/10.1002/2014ja020773

Yuan, T., Y. Zhang, X. Cai, C.-Y. She, and L. J. Paxton (2015), Impacts of CME induced geomagnetic storms on the midlatitude mesosphere and lower thermosphere observed by sodium lidar and TIMED/GUVI, Geophys. Res. Lett., 42, 7295-7302,doi:10.1002/2015GL064860

Zaourar, N., Amory-Mazaudier, C., \& Fleury, R. (2017). Hemispheric asymmetries in the ionosphere response observed during the high-speed solar wind streams of the 24-28 August 2010. Advances in Space Research, 59(9), 2229-2247. https://doi.org/10.1016/j.asr.2017.01.048 
Zaka, K. Z., Kobea, A. T., Doumbia, V., Richmond, A. D., Maute, A., Mene, N. M., et al. (2010). Simulation of electric field and current during the 11 June 1993 disturbance dynamo event: Comparison with the observations. Journal of Geophysical Research: Space Physics, 115(A11), n/a-n/a. https://doi.org/10.1029/2010ja015417

Zhang, Y. (2003). Negative ionospheric storms seen by the IMAGE FUV instrument. Journal of Geophysical Research, 108(A9). https://doi.org/10.1029/2002ja009797

Zhang, Y., L. J. Paxton, D. Morrison, B. Wolven, H. Kil, C.-I. Meng, S. B. Mende, and T. J. Immel (2004), O/N2 changes during 1-4 October 2002 storms: IMAGE SI-13 and

TIMED/GUVI observations, J. Geophys. Res., 109, A10308, doi:10.1029/2004JA010441. 


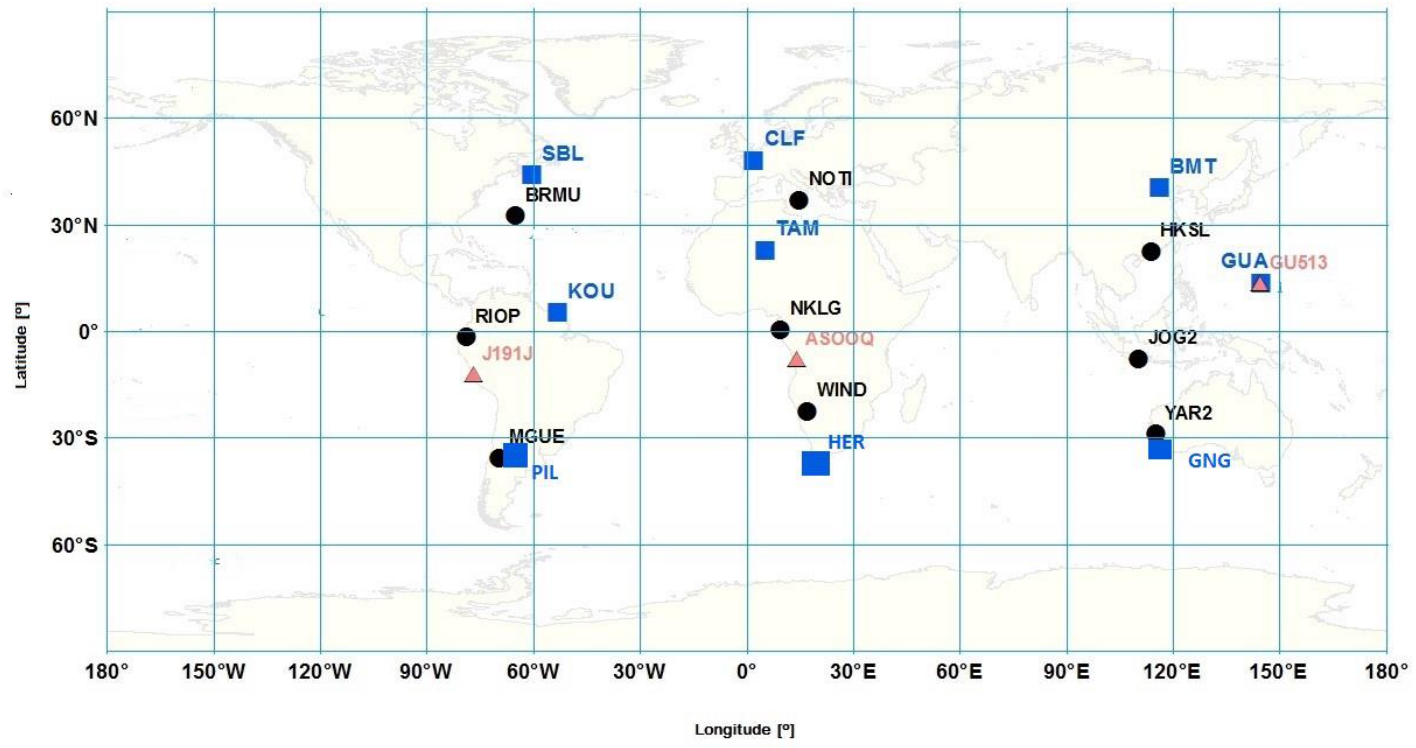

Figure 1: Location of the GNSS receivers (black) and magnetometer observatories (blue) used in the analysis. 


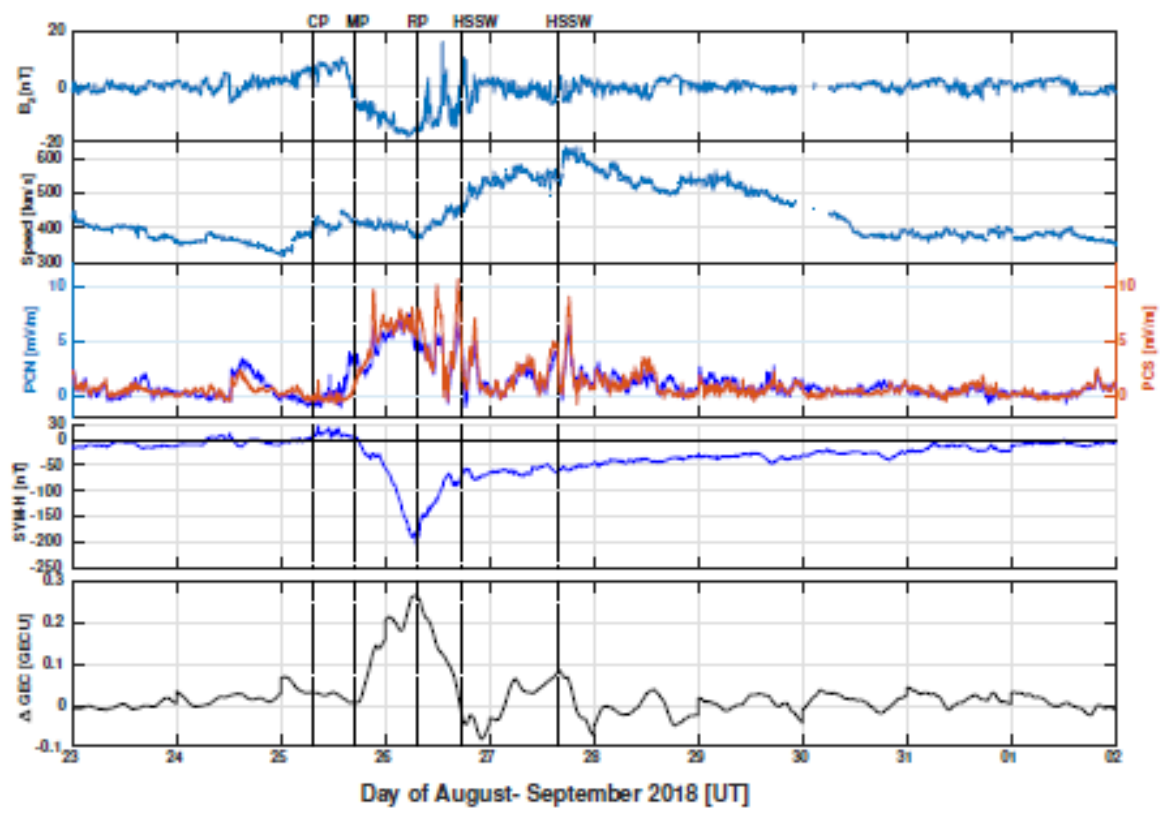

Figure 2: Global parameters, from 23 August to 01 September: (from top to bottom) the $B_{z}$ component of IMF in nanotesla, the solar wind speed in $\mathrm{km} / \mathrm{s}$, the SYM-H index in nanotesla, Polar cap indices in $\mathrm{mV} / \mathrm{m}$ and GEC in GECU.

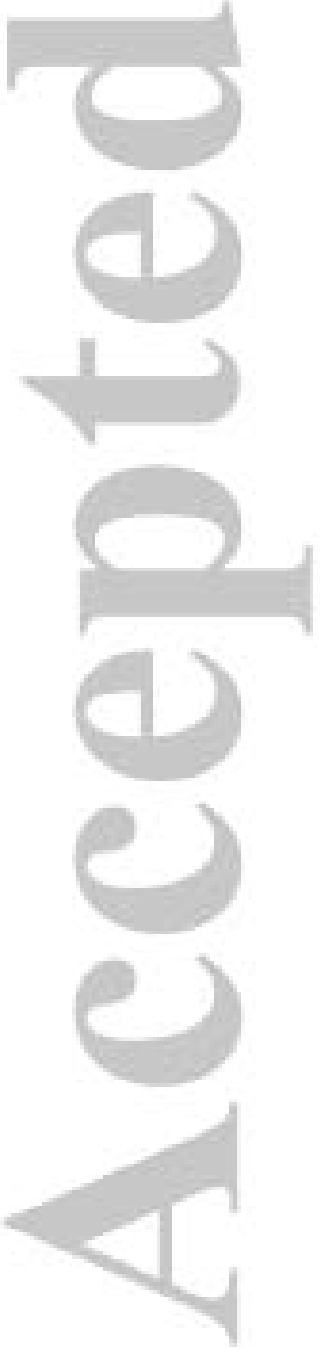



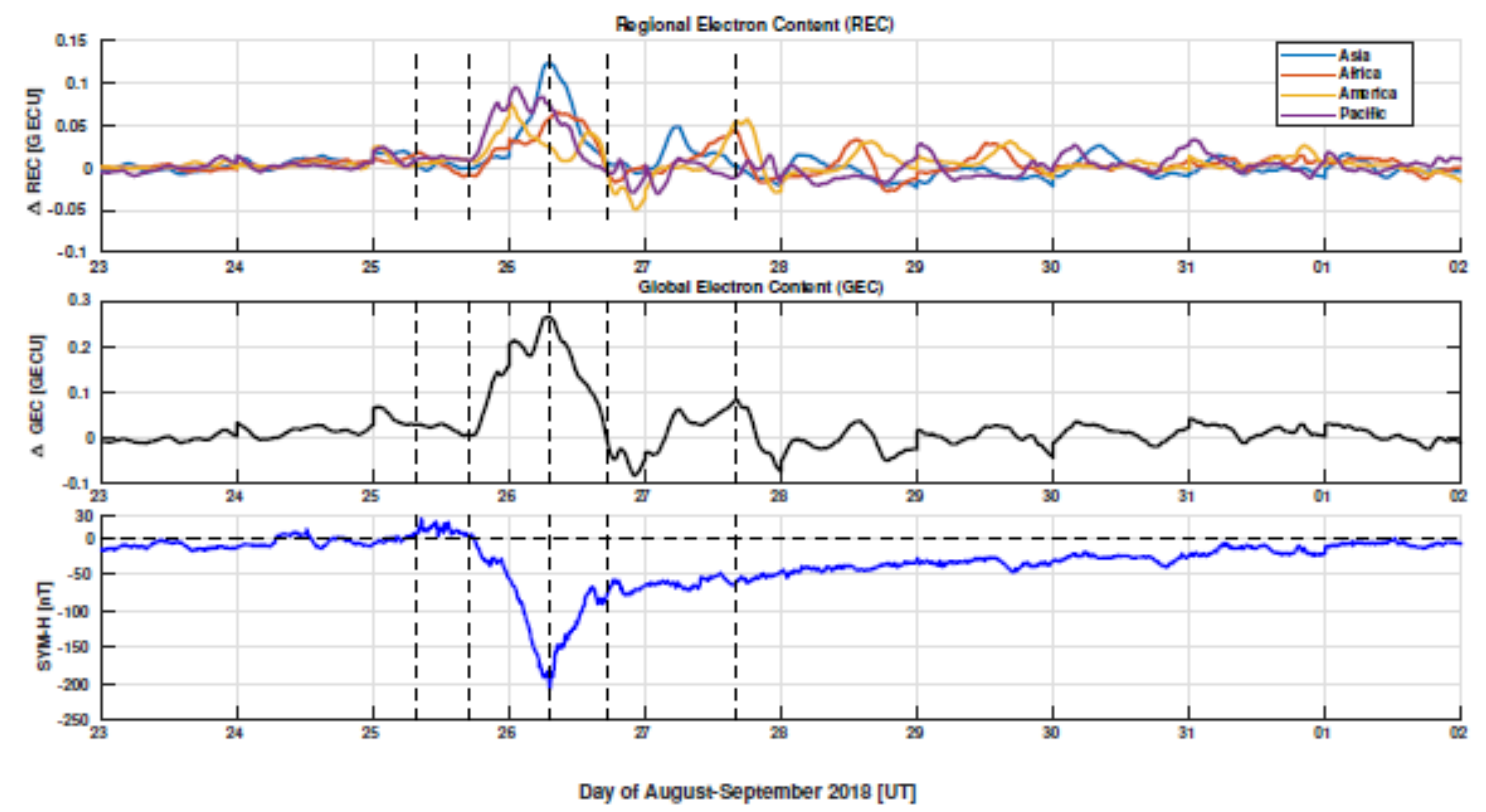

Figure 3: $\triangle \mathrm{REC}$ in the four longitudinal sectors Asia, Africa, America, and Pacific (top panel), $\triangle$ GEC (middle panel) and SYM-H index (bottom panel) from 23 August to 01 September 2018.

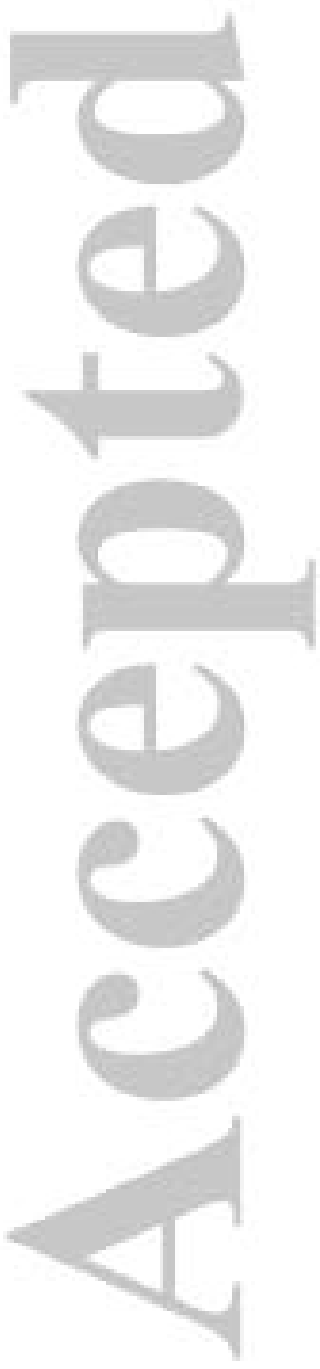

C2020 American Geophysical Union. All rights reserved. 

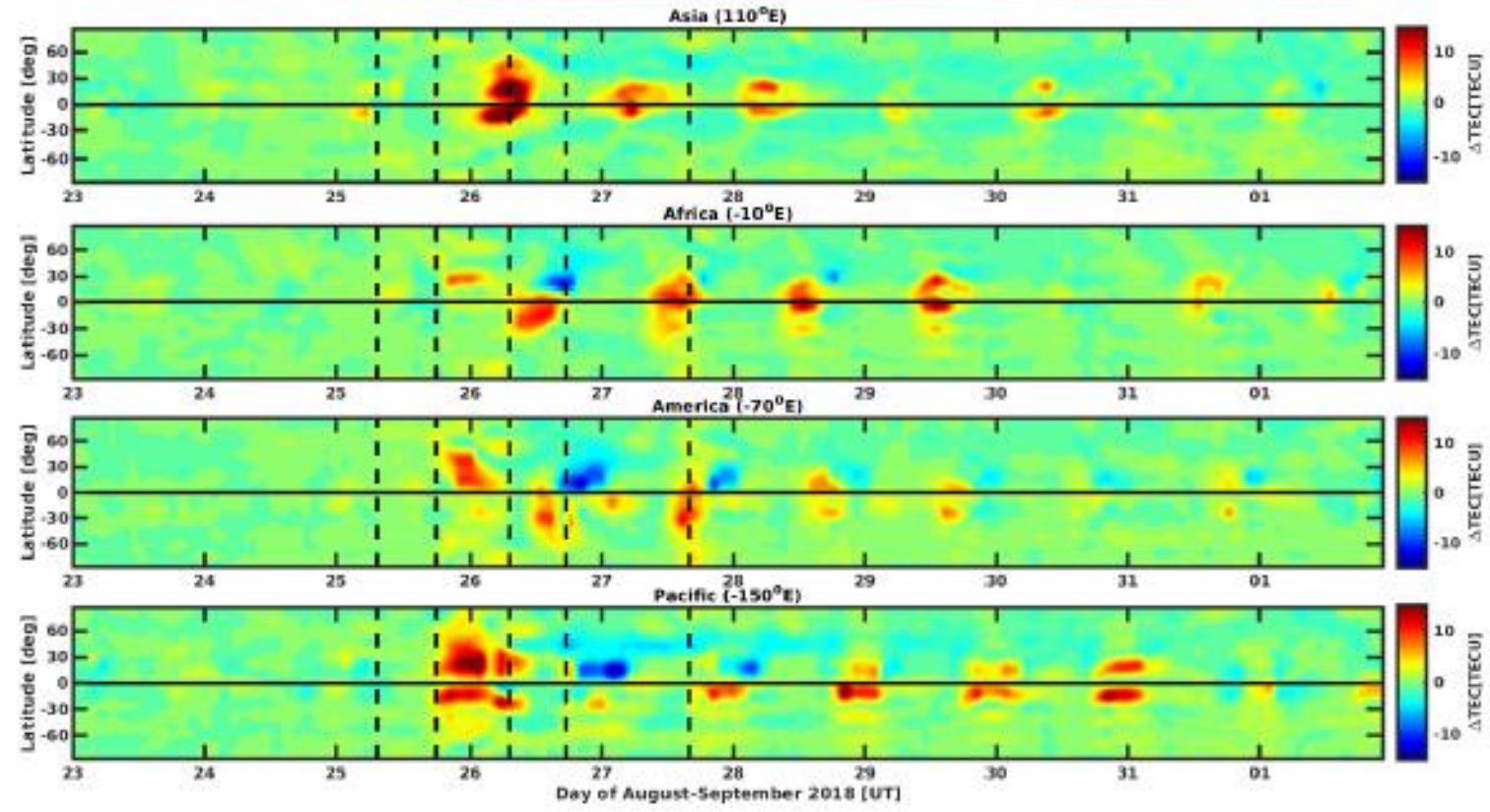

Figure 4: $\triangle V T E C$, in four longitudinal sectors (from top to bottom) Asia, Africa, America and Pacific from 23 August to 01 September 2018. 


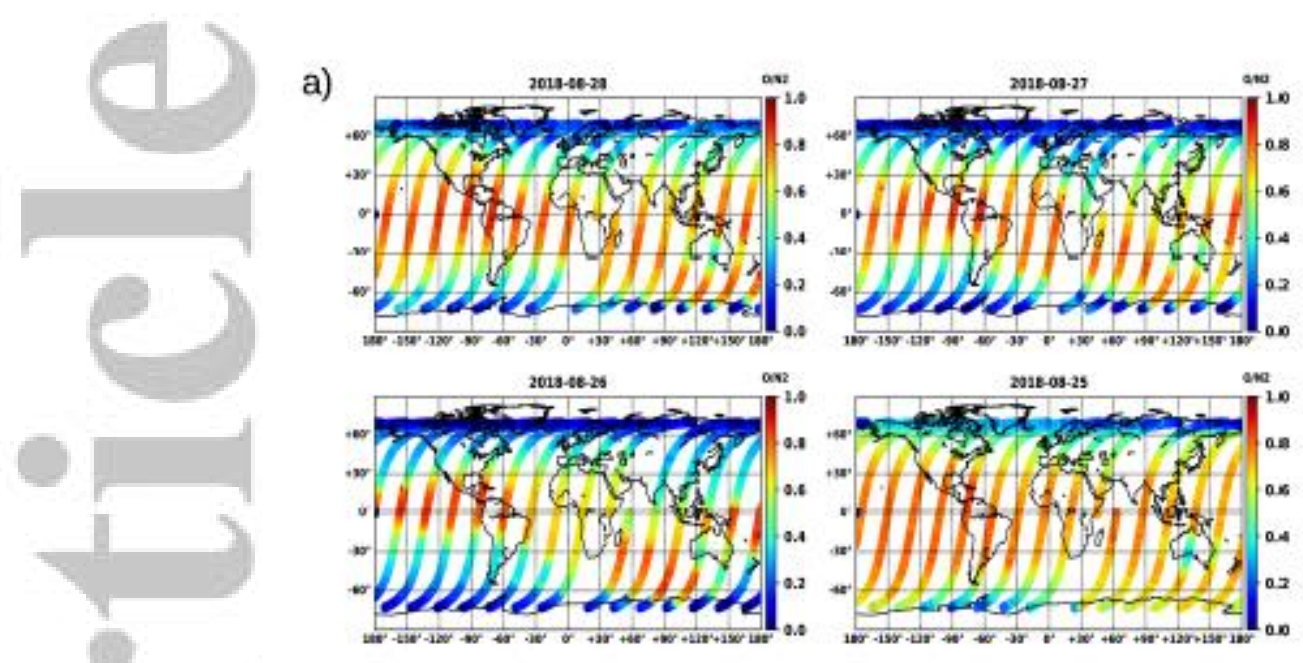

b)

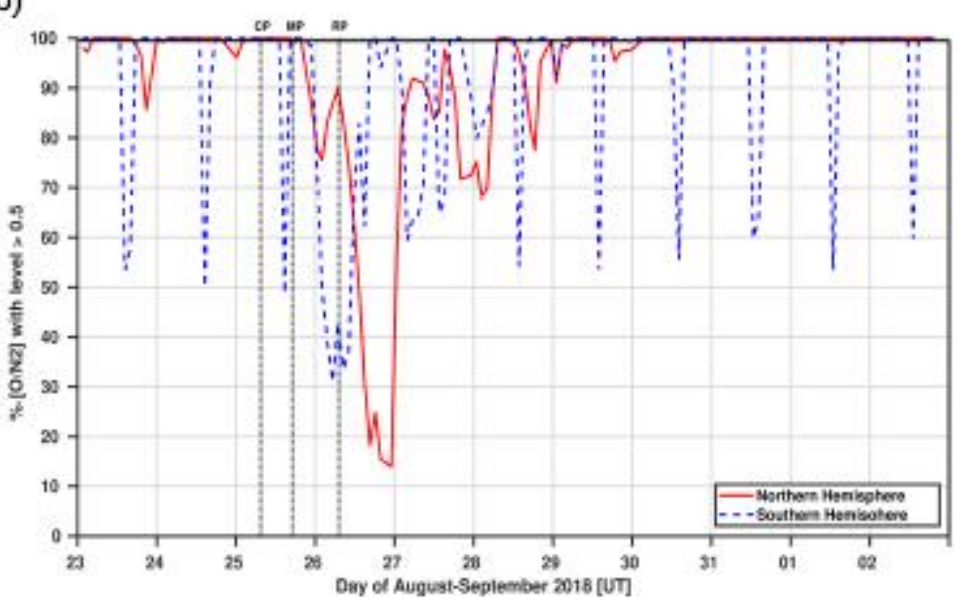

Figure 5: a) Thermospheric [O/N2] ratio from GUVI for a period 25-28 August 2018, b) Percentage decrease in [O/N2] ratio levels $>0.5$ in both hemispheres for the period 23 August to 02 September 2018. 

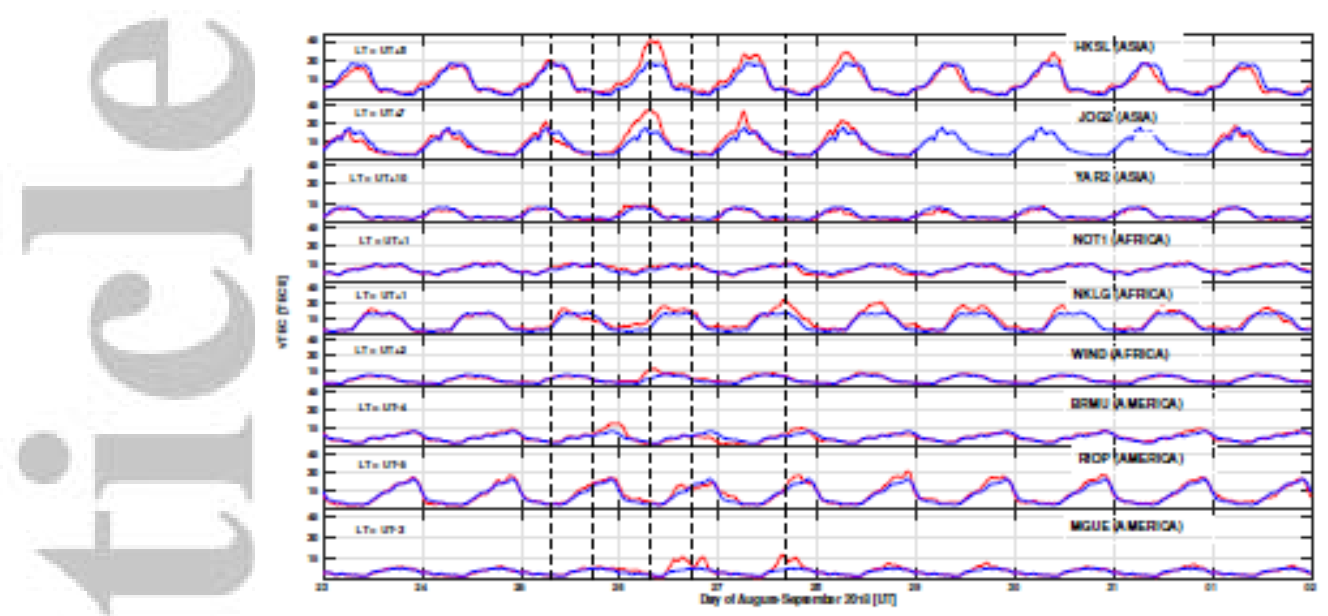

Figure 6: VTEC from 23 August to 01 September in Asian, African and American sectors. Each panel shows the observed VTEC (red) superimposed by the daily averaged value (blue).

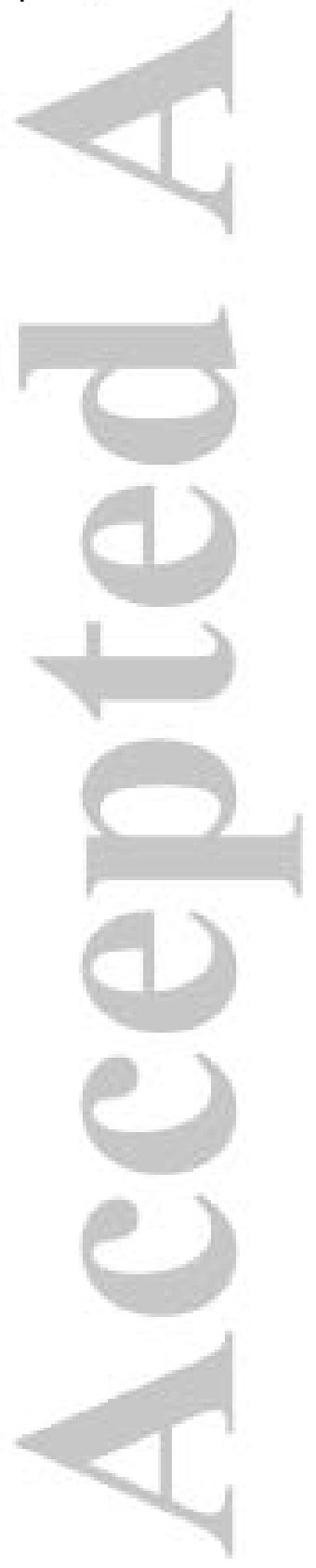

(C2020 American Geophysical Union. All rights reserved. 

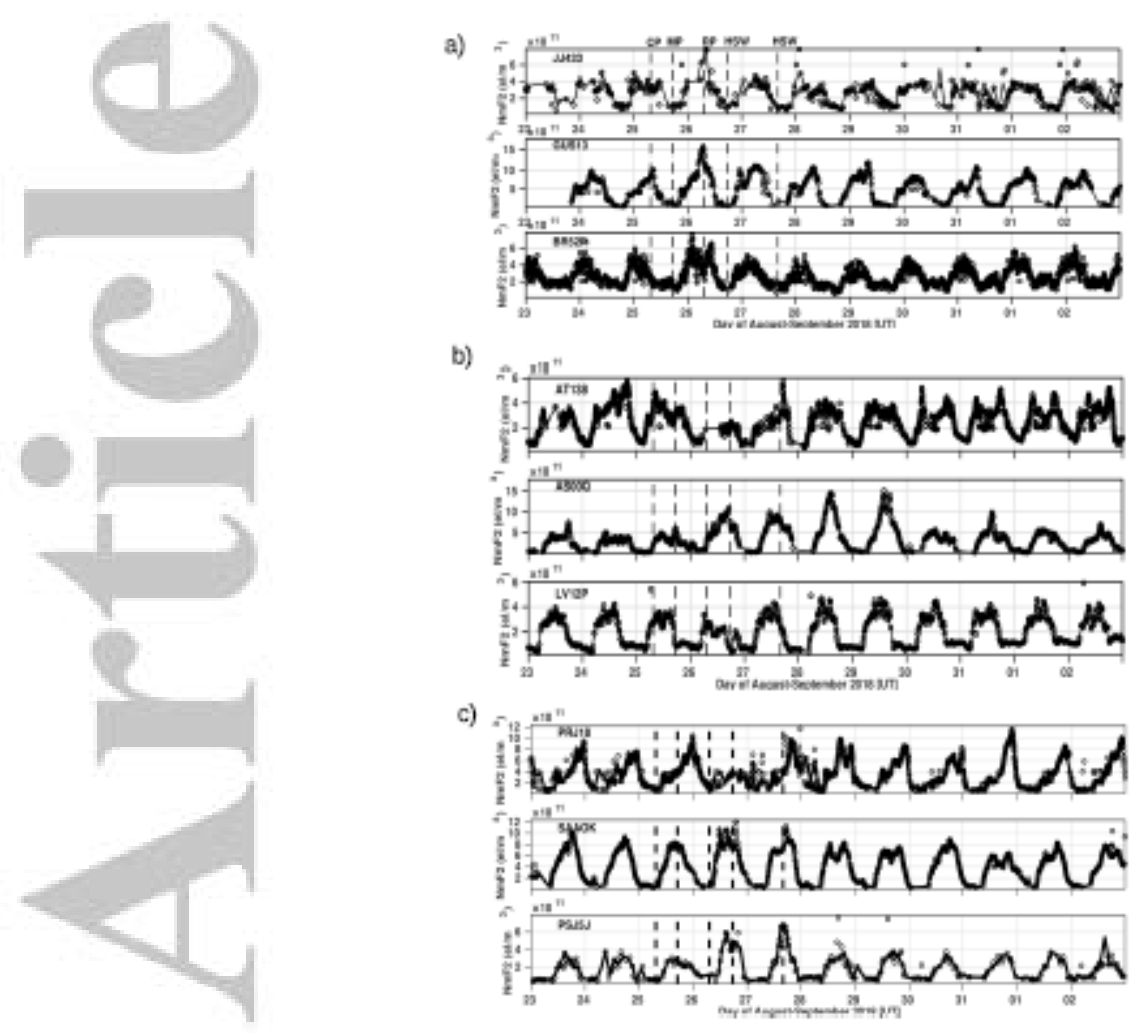

b)
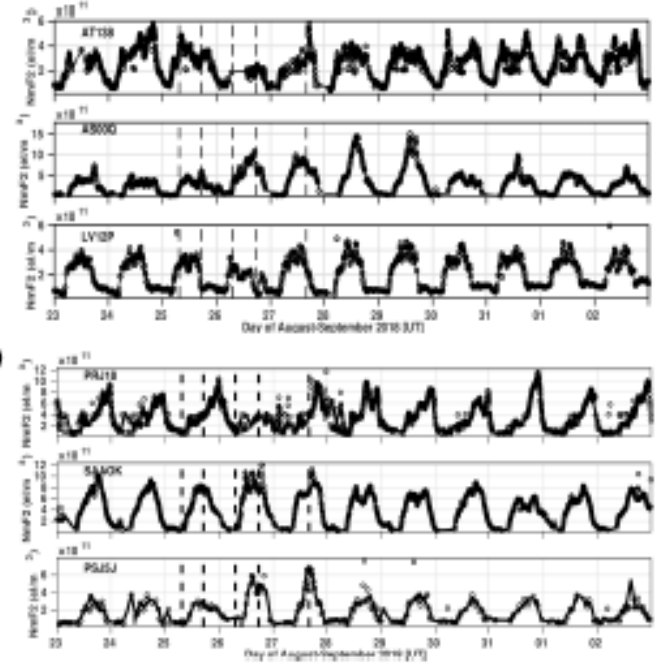

Figure 7: a) NmF2 variations in Asian sectors, from 23 August to 02 September 2018. From top to bottom, the panels correspond to JJ433 (north), GUS13 (equat) and BR52P (south) stations b) Same as Figure 7a for three ionosondes in the African sector: AT138, ASOOQ and LV12P, c) Same as Figure 7a for three ionosondes, namely, PRJ18, SAAOK and PSJ5J in the American sector, 


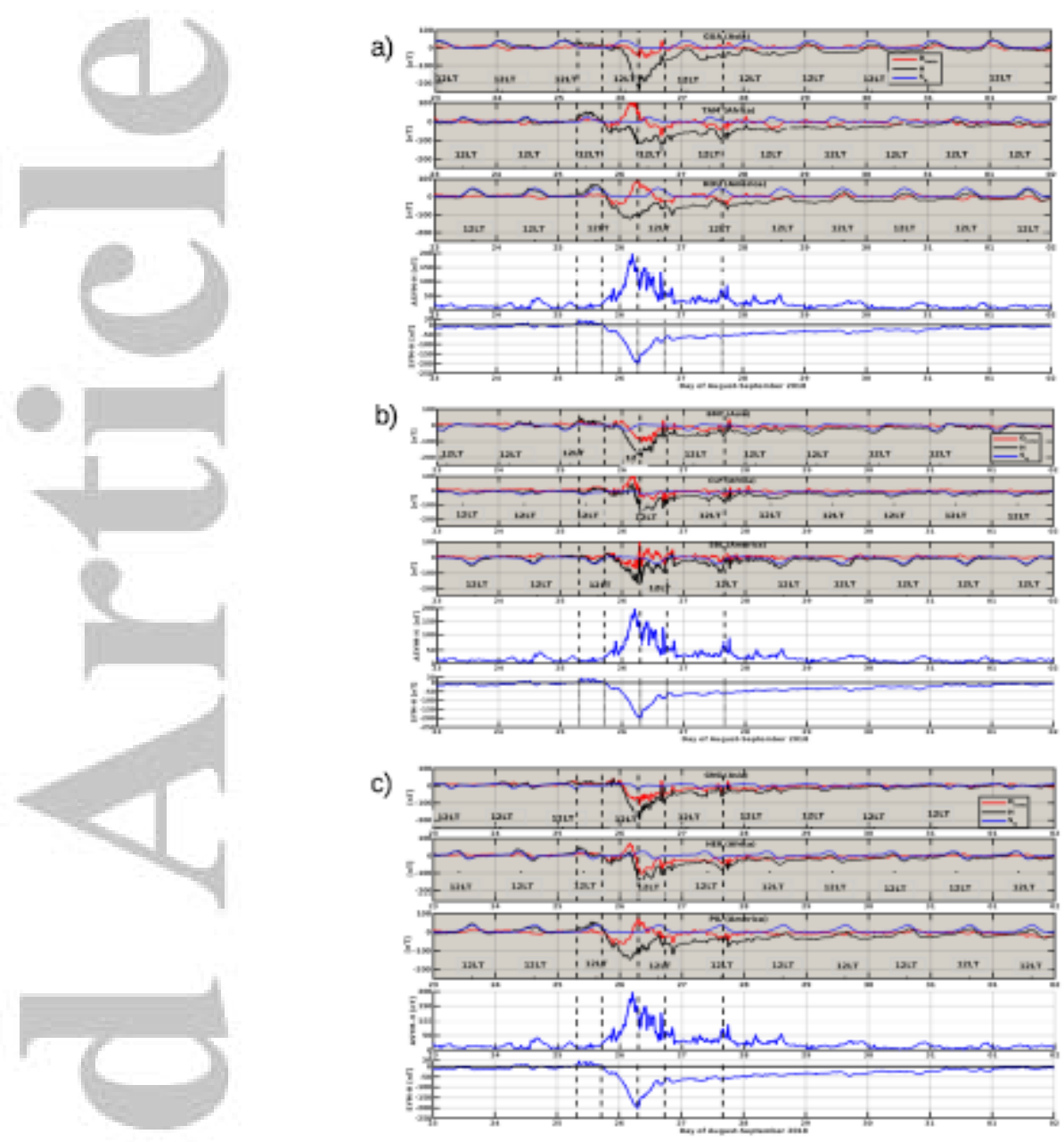

Figure 8: a) Low-latitudes magnetometer $\mathrm{H}$ variations in specific longitudinal sectors, from 23 August to 01 September, 2018. From top to bottom, the panels correspond to GUA (Asian sector), TAM (African sector), KOU (American sector), ASYM/H index and SYM/H index. On each panel, the observed $\mathrm{H}$-component (black) is superimposed by the regular Sq variations (blue) and the disturbed ionospheric electric currents $D_{\text {iono }}$ (red), b) Same as Figure $8 \mathrm{a}$ for three mid-latitudes magnetic stations in the northern hemisphere: BMT, CLF and SBL, c) Same as Figure 8a for three mid-latitudes magnetic stations in the southern hemisphere, namely GNG, HER and PIL. 

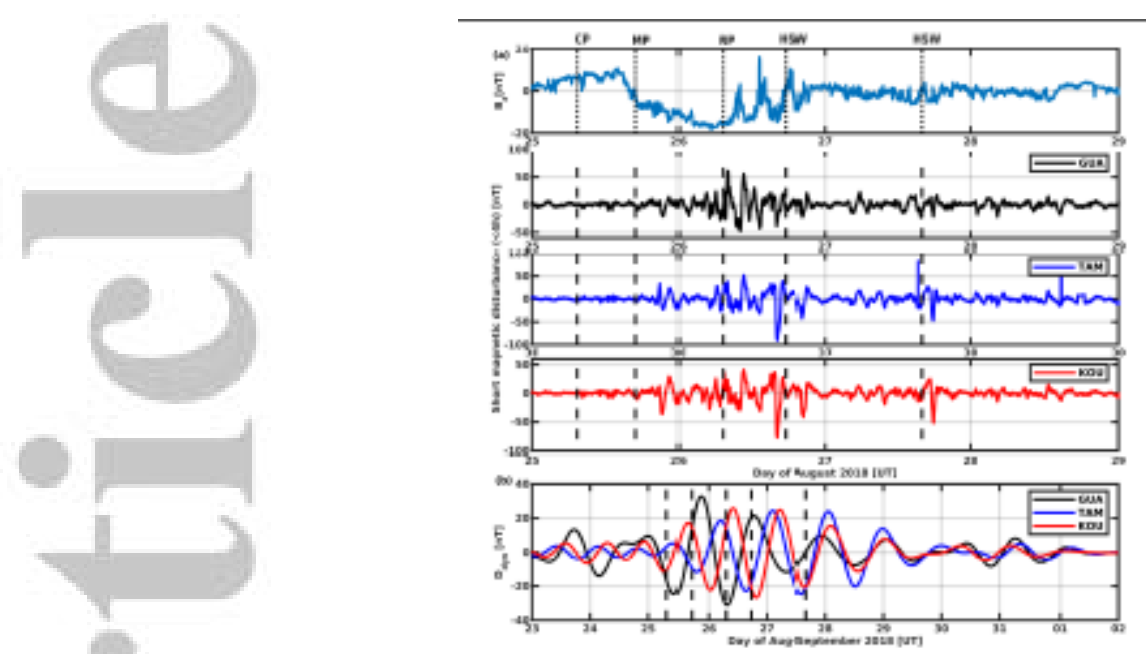

Figure 9: a) from top to bottom: $B_{z}$ component of IMF and Magnetic disturbance due to PPEF (DP2), in the Asian, African and American sectors from 25 to 29 August 2018 b) Magnetic disturbance $D_{\text {dyn }}$ at low latitudes stations in the different longitude sectors from 23 August to 02 September 2018.

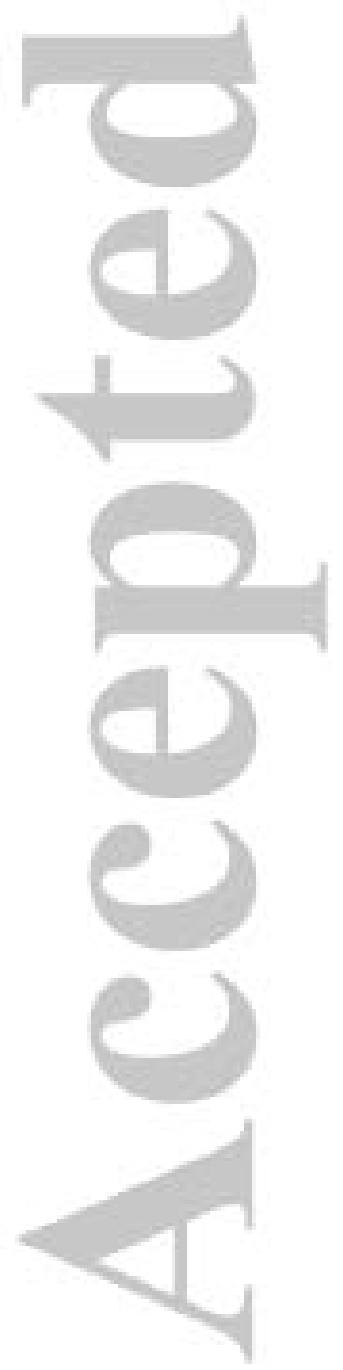


Table 1: The geographic latitudes, longitudes and the magnetic dip of the considered GPS stations.

\begin{tabular}{|c|c|c|c|c|}
\hline Station & Sector & Latitude & Longitude & Magnetic dip \\
\hline HKSL & Asia & 22.37 & 113.92 & 32.51 \\
\hline JOG2 & Asia & -7.77 & 110.37 & -32.82 \\
\hline YAR2 & Asia & -29.04 & 115.34 & -63.03 \\
\hline NOT1 & Africa & 36.87 & 14.98 & 51.77 \\
\hline NKLG & Africa & 0.35 & 9.67 & -26.03 \\
\hline WIND & Africa & -22.57 & 17.08 & -60.86 \\
\hline BRMU & America & 32.37 & -64.69 & 57.46 \\
\hline RIOP & America & -1.65 & -78.65 & 18.66 \\
\hline MGUE & America & -35.77 & -69.39 & -37.40 \\
\hline
\end{tabular}


Table 2: The geographic coordinates of the considered ionosondes.

\begin{tabular}{|r|c|c|c|c|}
\hline Station ID & Sector & Latitude & Longitude & Magnetic dip \\
\hline JJ433 & Asia & 33.43 & 126.30 & 49.30 \\
\hline GUS13 & Asia & 13.62 & 144.86 & 12.48 \\
\hline BR52P & Asia & -27.06 & 153.06 & -57.07 \\
\hline AT138 & Africa & 38.0 & 23.50 & 54.60 \\
\hline ASO0Q & Africa & -7.95 & -14.40 & -43.49 \\
\hline LV12P & Africa & -28.50 & 21.20 & -65.46 \\
\hline PRJ18 & America & 18.50 & -67.10 & 43.57 \\
\hline SAAOK & America & -2.60 & -44.20 & -9.95 \\
\hline PSJ5J & America & 51.60 & -57.90 & -49.97 \\
\hline
\end{tabular}


Table 3: The geographic coordinates of the considered magnetometers.

\begin{tabular}{|c|l|c|c|c|}
\hline Station ID & \multicolumn{1}{|c|}{ Sector } & Latitude & Longitude & Magnetic dip \\
\hline GUA & Asia & 13.59 & 144.87 & 12.35 \\
\hline BMT & Asia & 40.30 & 116.20 & 59.73 \\
\hline GNG & Asia & -31.32 & 115.71 & -65.38 \\
\hline TAM & Africa & 22.79 & 5.53 & 27.24 \\
\hline CLF & Africa & 48.02 & 2.27 & 63.53 \\
\hline HER & Africa & -34.43 & 19.23 & -65.23 \\
\hline KOU & America & 5.21 & -52.93 & 16.32 \\
\hline SBL & America & 43.94 & -60.11 & 65.10 \\
\hline PIL & America & -31.40 & -63.88 & -34.35 \\
\hline
\end{tabular}


Table 4: Percentage increase/Decrease in VTEC from average daily values at GPS stations.

\begin{tabular}{|l|l|l|l|l|}
\hline Station & Sector & 26 August & 27 August & 28 August \\
\hline HKSL & Asia & $+62 \%$ & $+37 \%$ & $+32 \%$ \\
\hline JOG2 & Asia & $+57 \%$ & $+31 \%$ & $+17 \%$ \\
\hline YAR2 & Asia & NA & NA & NA \\
\hline NOT1 & Africa & $-27 \%$ & $-37 \%$ & NA \\
\hline NKLG & Africa & $+56 \%$ & $+49 \%$ & NA \\
\hline WIND & Africa & $+89 \%$ & NA & \\
\hline BRMU & America & $+59 \%$ & $-48 \%$ & NA \\
\hline RIOP & America & NA & NA & $+31 \%$ \\
\hline MGUE & America & $+96 \%$ & $+123 \%$ & \\
\hline
\end{tabular}

